\title{
Le bonheur au bout de ma plume
}

\section{Françoise Lalande}

Sans doute aucun

il se trouve au fond de moi, à la manière d'un secret, le souvenir d'une douleur.

Il se trouve au fond de moi quelque chose qui fait mal, une blessure qui ne voudrait jamais guérir, comme si la guérison même de ce qui me tourmente paraitrait scandaleuse, or, la guérison ne serait scandaleuse que pour moi seule.

C'est étrange comme un écrivain peut serrer contre son cœur ce qui le blesse!

Comme il s'y accroche sa vie durant et malgré lui!

Cela fait mal, mais perdre cette chose blessante serait dangereux, ce serait comme une perte de son histoire, aussi terrible que de perdre son visage suite à un accident : on serait devenu étranger à soi-même.

Dans ce cas, on perdrait ce qui constitue l'écriture.

L'écriture :

une manie mystérieuse faite de recherches âpres du mot juste et de la vérité du texte tout entier.

Pourquoi dès l'enfance, petite fille seule, mise au lit alors que je n'avais pas sommeil, je me suis raconté des histoires tristes que je reprenais chaque soir pour en intensifier la tristesse, nuit après nuit, j’ai inventé une série de récits dont j'étais le personnage principal, je dis bien «le personnage principal » et non «l'héroïne » car le terme d'héroïne laisserait entendre que je triomphais dans mes récits, alors que non!, vraiment non!, toutes les calamités me tombaient dessus tous les chagrins étaient pour moi, jusqu'à mon cœur qui était malade un cœur recouvert de plusieurs peaux qui l'enserraient peu à peu, la mort s'annonçait, mais... n'arrivait jamais, j'inventais une opération miracle, 
qui coûtait très cher

et que celui qui m'aimait devrait payer.

Aujourd'hui, je me souviens que cette opération de mon cœur qui serait épluché comme une mangue constituait, dans mon esprit vindicatif, la plus raffinée des vengeances.

D'où me venait cette propension à choisir des abîmes?

Je peux affirmer que dès le départ, donc dès mes origines multiples,

j’ai su que mon désir de fiction se nourrirait de cette douleur secrète.

Secrète, mais non incompréhensible.

Chaque enfance est bercée par des chansons.

Les miennes parlaient de guerre, d'arrestation par la Gestapo

de la cousine préférée de ma mère, des camps où René et Johnny

furent internés.

«Ce n'était pas Auschwitz, mais c'était quand même l'enfer »

Voilà ce qui berça mon enfance.

Cette chanson-là.

Ou le silence.

Famille meurtrie, famille de silence.

Et, curieusement, dans la bibliothèque familiale,

Peu de romans, mais des grammaires et des dictionnaires en quantité.

Je me suis nourrie de tout cela, récits de guerre, silence et dictionnaires.

J'ai tout enregistré, tout avalé et, bien sûr, tout réinventé.

Parce que, pour moi, c'est cela, être écrivain!

S’emparer du réel pour le réinventer.

Nous le faisons tous!

Dès que nous racontons ce que nous avons vu, ce que nous avons vécu, une insidieuse transformation du réel s'opère.

Le fameux «mentir-vrai» d'Aragon s'accroche à la plume des écrivains comme la neige aux pattes des oiseaux.

Cette transformation mystérieuse à lui-même, l'écrivain la subit, elle conduit son texte vers une vérité profonde.

Je parle évidemment des écrivains pour qui l'écriture constitue d'abord une plongée au plus profond de leur être.

Je ne parle pas des écrivains qui se nourrissent uniquement, et pourquoi pas, de ce qui leur vient de l'extérieur. 
On ne produit pas le même texte si on part de ses profondeurs obscures ou si on parle de ce qui est enregistré de l'extérieur.

Pour ma part, j'appartiens à la catégorie des écrivains qui extirpent!

Qui arrachent!

Qui s'opèrent!

Alors arrive une sorte de miracle : le bonheur!

Car, au bout de ma plume, s'est assis, à la manière d'un Djinn, d'une fée, le bonheur.

Il ne guide pas mon écriture, il en est le résultat, c'est autre chose.

Il m'est impossible de décrire des douleurs, de parler de l'amour difficile (les personnages de mes romans à qui je donne le nom de ma famille maternelle, Keil, sont tous des "handicapés de l'amour»), d'évoquer les combats contre soi-même, de mettre en fiction le désir de passion, de dénoncer les blessures infligées aux faibles de la société, tout cela, oui, il m'est impossible de l'écrire si, à l'horizon de mon texte, je n'aperçois pas la lumière du bonheur, oui, il me faut l'espérance, pour mes personnages, pour moi, pour mes lecteurs.

Même mes romans les plus «noirs", se terminent par un renouveau, ils sont porteurs d'une possibilité de bonheur.

L'écriture n'a pas aboli la douleur en moi, elle l'a rendue supportable.

Alors, je dois ici remercier qui? Et pour quelle raison?

Parce qu'il y a chez moi une faculté première à voir et à vivre les choses de la vie avec humour.

Cela ne peut me venir de ma famille, je le promets!, au contraire, les membres de ma famille maternelle ont pris tout ce qui leur arrivait, même après la fin de la guerre, avec pessimisme et mécontentement généralisé.

Peut-être que ce qui a mis le bonheur au bout de ma plume est mon empathie pour les gens, mon amour pour les malmenés de l'Histoire, les faibles, enfants, hommes et femmes, mon indignation devant les souffrances des hommes.

Lorsque je m'empare d'un sujet de cet ordre, presque toujours j'en appelle à l'humour pour donner de l'air à ce qui pourrait m'étouffer et étouffer le lecteur.

Du Noir, ouil, mais aussitôt du rire, de l'humour. 
Souvent, tout en écrivant, je ris de ce que j'ajoute au récit. Le personnage qui trébuche sur les pavés irréguliers de la rue, qui peste de s'être quasi tordu le pied, alors qu'au bout de cette même rue, l'attend le pire.

Je m'amuse du décalage entre l'importance donnée à un fait mineur et l'ignorance du fait majeur qui attend mon personnage au coin de la rue... j’ai envie de dire au coin de ma plume évidemment.

C'est une chose étrange, l'écriture.

C'est un être étrange, un écrivain.

Mais le bonheur est là. Un autre écrivain peut ne pas ressentir ce bonheur. Mais pour ma part, la douleur d'écrire, je ne sais pas ce que c'est.

Le bonheur, oui.

Il est fait d'exaltation de l'esprit et du corps quand, enfin, après avoir supprimé des phrases, détruit des chapitres, changé un mot pour un autre, et puis non! finalement je mettrai ce mot-là, je me sens fatiguée, mais encore insatisfaite, je sens que le texte me résiste, il ne me vaincra pas, je résiste moi à le jeter par la fenêtre, à en faire une cocotte en papier, par vengeance, je redeviens un enfant qui n'aime pas qu'on s'oppose à sa volonté, et puis, ça y est!, vient sous ma plume, comme coulant de source, la formulation heureuse.

Pour quelle raison est-elle « heureuse »?

Parce qu'elle a un rythme, une musique, celle qui donnera à mon roman son phrasé poétique.

Pour moi, c'est l'essentiel.

Le poétique de mes phrases, donc du récit tout entier.

Il ne m'a pas été donné.

J'ai dû le chercher.

J'ai dû aussi contrecarrer le goût de certains éditeurs qui voulaient une écriture «classique » et se montraient frileux devant mes longues phrases sans point, seule la virgule, la si jolie virgule, ponctue la respiration de moi « écrivant», donc, après moi, de celle ou de celui « lisant».

J'ai respiré comme ont respiré les écrivains qui m’ont construite. Mes lectures de Rimbaud, de Proust, de Joyce, de Joseph Conrad furent des lectures-respirations fraternelles.

Fureur adolescente et musique moderne du génial enfant de Charleville. Rosseries sociales et longue musique ondoyante comme des algues marines chez Proust. La musique dans toutes ses variations chez l'époustouflant Joyce. La cruauté humaine comme principe d'écriture dans les vastes 
opéras du marin Conrad.

Oui, pour moi, l'écriture est bonheur.

L'écriture a construit, et construit toujours, mon rapport au monde.

L'écriture a donné à ma vie de la force et de la beauté.

L'écriture, aujourd'hui, alors que je me sens vaciller, m'offre encore et toujours les plus belles pépites de bonheur. 